\title{
Sugestão de Etapas para a Estruturação da Gestão Empresarial de Pequenas Empresas
}

\author{
Thomaz Martins de Aquino ${ }^{1}$, Luciano Thomé e Castro ${ }^{2}$ \\ ${ }^{1}$ Faculdade de Economia, Administração e Contabilidade de Ribeirão Preto (USP) - \\ thoomaz.martins@gmail.com \\ ${ }^{2}$ Faculdade de Economia, Administração e Contabilidade de Ribeirão Preto (USP) - \\ lucianothomecastro@gmail.com
}

\section{KEYWORDS}

Modelo de gestão;

Pequena empresa;

Estratégia.

Received 17.08.2017

Revised 11.10.2017

Accepted 28.11.2017

ISSN 1980-4431

Double blind review

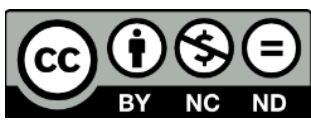

ABSTRACT

Sendo a gestão compreendida como a forma que empresas organizam suas atividades, conduzem seu trabalho, alcançam seus objetivos e devem agir em situações diversas, este trabalho teve como objetivo identificar as etapas necessárias para a construção de uma gestão empresarial em pequenas empresas. Para tal, realizou-se uma revisão da literatura sobre métodos conhecidos, como Balanced Scorecard, Business Process Management, Modelo de Excelência da Gestão, PDCA e Business Model Canvas. Seguindo por uma análise comparativa entre as diferentes metodologias a fim de identificar quais as atividades de gestão mais recorrentes. Entre os principais resultados está a elaboração de um framework de sugestão para as boas práticas de gestão, dividido em 5 grupos de atividades relacionados às fases lógicas da gestão empresarial: Visão de Futuro, Entrega de Valor, Atribuição de Responsabilidades, Controle de Recursos e Crescimento de Longo Prazo. Assim, sugere-se que um trabalho futuro interessante seria a aplicação do modelo seguido por estudo de caso para averiguar o grau de efetividade na organização.

\section{Introduction}

The Empresa é a atividade organizada pelo sujeito de direito, chamado empresário, e desenvolvida mediante o instrumento adequado (BARRETO, 1988). É um organismo capaz de praticar a ação econômica, não se confundindo com a mesma (SOUZA, 1977). As empresas se diferem pelo faturamento, onde, de acordo com a Lei número 123/2006 das Micro e Pequenas Empresas (MPEs) as microempresas brasileiras são àquelas que possuem um faturamento anual limitado em até $\mathrm{R} \$ 240$ mil ao ano e, segundo mesma lei, as pequenas empresas podem faturar até $\mathrm{R} \$ 2,4$ milhões anualmente.

La Rovere (1999, p.145) aponta que "até meados dos anos 70, as pequenas e médias empresas (PMEs) tinham papel pequeno sobre o desenvolvimento econômico devido ao predomínio do paradigma de produção em massa", passando a ter expressividade a partir do desenvolvimento das novas tecnologias da informação e comunicação que revolucionaram as relações econômicas e socioculturais (ALBAGLI, 1999). Dessa forma a participação das MPEs cresceu de $21 \%$, em 1985, para $27 \%$ do PIB brasileiro em 2011, gerando mais da metade dos empregos formais no país (SEBRAE, 2014).

Apesar do crescimento das PMEs, 26,9\% das empresas com até dois anos encerram suas atividades (SEBRAE-SP, 2010). Taxa de mortalidade que chegou a $54 \%$ entre as microempresas em 2009 (BEDÊ, 2016). Em estudo realizado com 2.006 empresas o Sebrae concluiu que os fatores principais para a sobrevivência, e consecutivamente a falta deles para a mortalidade,

Revista de Negócios, v. 21, n. 3-4, p. 39-51, July, 2016. 
estavam ligados a situação do empresário antes da abertura (como tipo de ocupação e experiência no ramo), planejamento do negócio, gestão do negócio e a capacitação dos donos sobre gestão empresarial (BEDÊ, 2016). Ou seja, três dos quatro aspectos críticos apresentados estão relacionados a forma que é realizada a gestão empresarial.

Como o ato de gerir é realizado através de um exemplo já existente, realizando apenas as modificações necessárias para a necessidade de cada organização (FERREIRA et al., 2009), entende-se que pequenas empresas devem apresentar etapas particulares para a organização de suas atividades, recursos, procedimentos, normas e regras.

Assim, vistas as particularidades das pequenas empresas, e os conceitos de gestão, a pergunta à qual essa pesquisa pretende responder é: Quais as etapas necessárias para a construção de uma estrutura de gestão empresarial em empresas de pequeno porte?

A suposição é que os métodos consagrados de gestão, e seus respectivos modelos de referência, não se comunicam a fim de criar uma estrutura de gestão integrada. Dessa forma, o objetivo central deste trabalho é analisar os modelos de gestão existentes, diferenciando-os a fim de permitir a identificação de suas atividades para uma sugestão consolidada das etapas de construção da gestão empresarial.

Entender que conceitos de gestão amplamente difundidos podem contribuir para uma melhoria dos resultados entregues tanto por grandes organizações quando por pequenas empresas é um ganho de maturidade significativo presente neste estudo. Por essas razões, a realização deste trabalho representa uma contribuição para empresas de pequeno porte e à pesquisa na área de gestão.

Assim, o artigo está fundamentado em seis partes. Inicialmente apresenta-se esta explanação breve e introdutória. A seguir será exposto o referencial teórico sobre modelo de gestão e o que se espera que uma organização, de modo geral, deva fazer. Em um terceiro momento aborda-se a metodologia utilizada para a pesquisa. Em quarto lugar uma análise individual dos modelos estudados é exposta. Em quinto, os resultados que respondem a pergunta e objetivo apresentado. Por fim, uma breve reflexão sobre o trabalho e sugestão de pesquisa futura.

\section{Referencial Teórico}

\subsection{Modelo De Referência De Gestão}

O modelo de referência de gestão não costuma ser visível aos funcionários, tornando-se algo implícito à organização (RODRIGUEZ, 2010). Porém, Rodriguez (2010) afirma que a existência de um modelo é necessária para o adequado funcionamento empresarial, sendo a forma, estruturada e organizada, como ocorre a integração entre os sistemas internos e assegura o atendimento às estratégicas do negócio.

Independente do modelo de gestão adotado, duas dimensões estão sempre presentes: a "forma" e a "função" (FERREIRA et al., 2009). A Forma expressa a configuração organizacional e a Função as tarefas que precisam ser cumpridas.

No Brasil, a necessidade de se adotar padrões e modelos internacionais para orientar e avaliar a gestão foi apontada na década de 90, dando início a história sobre modelos de referência de gestão no país (FNQ, 2012). Um grupo formado por representantes de 39 organizações, privadas e públicas, instituiu a Fundação para o Prêmio Nacional da Qualidade, dedicada ao reconhecimento das boas práticas de qualidade pelas empresas nacionais. Transformando-se, em 2005, na Fundação Nacional da Qualidade (FNQ) que passou a difundir o que se conhece como Modelo de Excelência da Gestão (MEG) (FNQ, 2012).

O MEG apresenta 13 Fundamentos da Excelência (Quadro 1), que revelam padrões culturais das organizações de Classe Mundial e são reconhecidos internacionalmente (FNQ, 2013). "Os fundamentos, quando aplicados em sua plenitude, estão internalizados na cultura e presentes em cada atividade da organização" (FNQ, 2008. p.8), sendo expressos por meio de seus processos gerenciais e consequentes resultados.

Quadro 1. Fundamentos da Excelência

\begin{tabular}{|c|c|c|}
\hline $\begin{array}{c}\text { Pensamento } \\
\text { sistêmico }\end{array}$ & Liderança transformadora & $\begin{array}{c}\text { Valorização } \\
\text { das pessoas e } \\
\text { da cultura }\end{array}$ \\
\hline $\begin{array}{c}\text { Atuação em } \\
\text { rede }\end{array}$ & Olhar para o futuro & $\begin{array}{c}\text { Orientação por } \\
\text { processos }\end{array}$ \\
\hline $\begin{array}{c}\text { Aprendizado } \\
\text { organizacional }\end{array}$ & $\begin{array}{c}\text { Conhecimento sobre } \\
\text { clientes e mercados }\end{array}$ & $\begin{array}{c}\text { Geração de } \\
\text { valor }\end{array}$ \\
\hline Inovação & Responsabilidade social & \\
\hline Agilidade & Decisões fundamentadas & \\
\hline
\end{tabular}

Fonte: Elaborado pelos autores. 
Tais fundamentos são desdobrados em requisitos tangíveis que se inserem dentro de um ciclo capaz de reproduzir de forma lógica a condução de um negócio. Onde,

"O direcionamento da organização, dado pela Liderança, ouvindo os Clientes e a Sociedade, é definido por meio das Estratégias e Planos; a sua implementação é realizada por meio das Pessoas, que compõem a força de trabalho, utilizando-se dos Processos existentes na organização; e todo esse ciclo, ao ser executado, deverá conduzir a Resultados, que devem ser analisados e entendidos, gerando Informações e Conhecimento para serem utilizados no processo de tomada de decisão, gerando um novo ciclo de gestão". (FNQ, 2008. p.10)

Pode-se notar que este ciclo apresentado pela FNQ segue uma sequência de planejamento, execução, avaliação e melhoria, fazendo um paralelo com o famoso ciclo plan, do, check, act (PDCA).

O PDCA teve origem como um ciclo de controle estatístico que poderia ser continuamente repetido sobre qualquer problema ou processo, partindo de uma sequência lógica de: Especificação (plan), Produção (do) e Inspeção (see) (SHEWHART, 1939). Com sua introdução no Japão a proposta inicial de três etapas foi alvo de objeções, levando a conclusão de que o original "plan, do, see" não era adequado, pela interpretação de que o verbo see (ver, olhar) representava uma ação passiva, apenas de inspeção (MARANHÃO; MACIEIRA, 2008).

Assim, o modelo adotado no Japão passou a ser o PDCA como conhecido hoje (figura 1), pois remete ao fato de que depois da execução ser verificada deve-se tomar ações de correção ou melhoria (HOSOTANI, 1992).

Figura 1. Ciclo PDCA como desenvolvido no Japão.
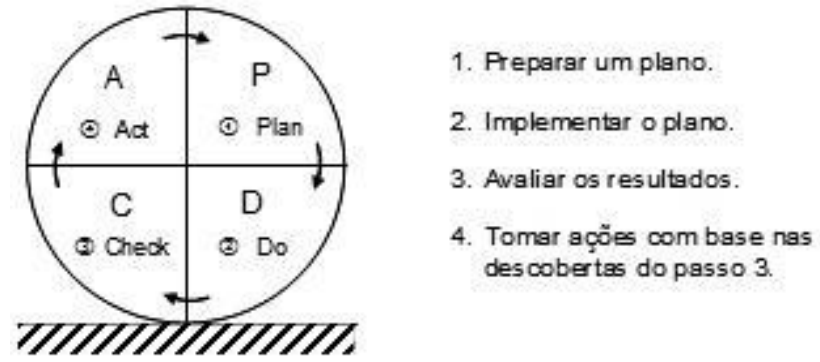

Fonte: Hosotani (1992).

De acordo com Nascimento (2011) o processo de Melhoria Contínua pode ser produzido usando o PDCA. Pois, quando a organização atingir seus padrões de excelência tais padrões deverão inferir em mudanças continuas, levando a uma melhoria constante dos processos.

Somente com a utilização do método de forma sistêmica, na organização como um todo, o crescimento de longo prazo será alcançado (FALCONI, 2013). Falconi (2013) aponta que uma organização é como um grande sistema de gestão, possuindo metas e melhorias a níveis estratégico, tático e operacional. O que possibilita que as metas do diretor estejam diretamente ligadas às metas de sua chefia, num relacionamento de causa e efeito.

\subsection{Conceitos e Ferramentas de Gestão}

A discussão de nível estratégico possui antecedentes na pré-história. Conforme as sociedades cresceram e os conflitos se tornaram mais complexos, capitães, generais e estadistas estudaram e testaram conceitos estratégicos essenciais, até o surgimento de um grupo coerente de princípios (MINTZBERG et al, 2006).

Atualmente a estratégia está orientada para uma visão prospectiva do ambiente e da empresa, para a obtenção e sustentação de vantagens competitivas (ZACCARELLI, 2000). Basicamente pode-se compreender a estratégia como um conjunto de diretrizes conscientemente deliberadas que orientam as decisões da organização (GIMENEZ et al., 1999).

O método de construção da estratégia mais difundido e reconhecido é o Balanced Scorecard, onde seu "mapa estratégico" (Figura 2) fornece uma sequência que conecta os ativos intangíveis com processos que criam valor para gerar resultados tangíveis (KAPLAN; NORTON, 2004). É composto por quatro perspectivas: financeira; do cliente; dos processos internos; e a perspectiva de aprendizado e crescimento.

Cada perspectiva apresenta objetivos conectados por relações de causa e efeito, como mostra a figura 2.

De modo sucinto, carecendo de profundidade, pode-se resumir a estratégia empresarial como definição e controle da Visão de Longo Prazo, acrescida de Objetivos e Iniciativas Estratégicas. O que levanta a discussão sobre a forma com que tal controle é realizado e de que modo o negócio funciona, a fim de atingir sua estratégia, ou seja, seu Tático.

Revista de Negócios, v. 21, n. 3-4, p. 39-51, July, 2016. 
Figura 2. O modelo do Balanced Scorecard

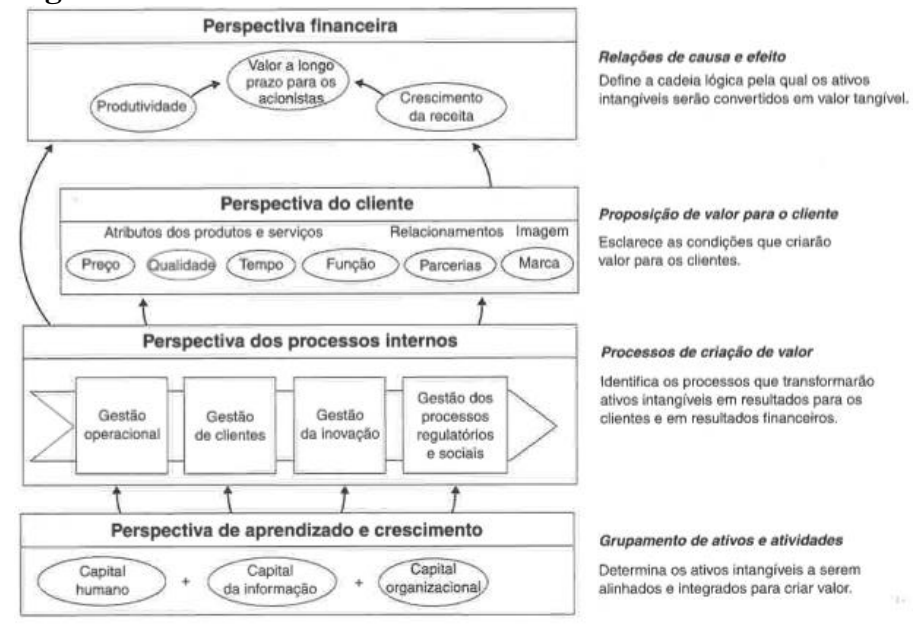

Fonte: Kaplan; Norton (2004).

De modo sucinto, carecendo de profundidade, pode-se resumir a estratégia empresarial como definição e controle da Visão de Longo Prazo, acrescida de Objetivos e Iniciativas Estratégicas. O que levanta a discussão sobre a forma com que tal controle é realizado e de que modo o negócio funciona, a fim de atingir sua estratégia, ou seja, seu Tático.

A esta etapa Dias et al. (2006, p.52) chama de modelo de negócio, ou "uma abstração do funcionamento do próprio negócio". "Um modelo de negócios descreve a lógica de criação, entrega e captura de valor por parte de uma organização" (OSTERWALDER; PIGNEUR, 2011. p.14).

Osterwalder (2004) identificou em sua tese de doutorado os principais pontos de um modelo de negócio. Frente aos extensos planos utilizados podendo alcançar mais de 100 páginas - seu trabalho revolucionou a forma com que organizações enxergam a criação de um novo negócio, consolidando tal estudo em um framework: uma tela esquemática que materializa a Business Model Canvas (OSTERWALDER; PIGNEUR, 2011), ferramenta de geração de modelos de negócio.

Osterwalder e Pigneur (2011) trouxeram para o setor uma característica pouco utilizada: o Pensamento Visual, com utilização de figuras, diagramas e Post-its ${ }^{\mathrm{TM}}$ para construção e discução. Segundo os autores modelos de negócios são conceitos complexos, compostos de vários componentes e da inter-relação entre eles, sendo assim é difícil compreender de fato um modelo sem que seja de uma forma visual.

A execução do modelo de negócio ocorre por meio dos processos organizacionais, retomando o nível operacional da discussão. O foco no estudo dos processos remonta ao início do século passado, com a melhoria de operações (TAYLOR, 1990), passando pela reengenharia no início da década de 1990, os movimentos da qualidade e pelo Sistema Toyota de Produção.

De acordo com Neubauer (2009), a gestão por processos é uma abordagem de gestão que permite às organizações uma maior facilidade de adaptação à continua necessidade das mudanças requeridas pela dinâmica do mercado e seus consumidores. Trata-se de uma abordagem que promove o desenvolvimento e a melhoria contínua das estratégias e táticas organizacionais, e que foca os esforços de gestão nas atividades do negócio que geram maior valor para o cliente (NEUBAUER, 2009).

Segundo Sordi (2008) os processos de negócio são fluxos de atividades, de diferentes áreas funcionais, ou mesmo de diferentes empresas, que geram algo de valor para seus clientes. Os processos de negócios determinam em grande parte a qualidade, o grau de inovação e a produtividade das organizações (MINONNE; TURNER, 2012), além disso, o desempenho de uma organização é mais eficaz quando a organização se concentra na gestão por processos (KANG et al., 2012).

Dessa forma, entende-se que os conceitos importantes para um modelo de gestão compreendem as perspectivas estratégicas, táticas e operacionais, além da melhoria contínua.

Apesar da divisão realizada neste referencial, e que se seguirá na etapa de revisão da literatura, é importante salientar que os diversos métodos e ferramentas não se prendem a uma única perspectiva.

\section{Método}

Este trabalho possui natureza predominantemente qualitativa, portanto seu desenvolvimento se dá por meio de uma revisão narrativa de modelos presentes na literatura, buscando identificar práticas utilizadas por modelos consolidados de gestão.

A revisão narrativa é considerada a revisão tradicional ou exploratória, onde não há a definição de critérios explícitos e preocupação em esgotar as fontes de informação (CORDEIRO et al., 2007). Tais revisões não adotam critérios a priori para a seleção das publicações, tratando-se da

Revista de Negócios, v. 21, n. 3-4, p. 39-51, July, 2016. 
interpretação da literatura existente de um determinado assunto de acordo com análise crítica do autor (ROTHER, 2007).

Assim, os procedimentos metodológicos para elaboração da pesquisa são compostos de duas fases que buscam responder às questões levantadas pelos objetivos da pesquisa: (1) Revisão da Literatura e Modelos de Gestão; (2) Elaboração de um Corpo Comum de Conhecimento. A figura 3 sintetiza o relacionamento entre objetivos e métodos utilizados.

Figura 3. Relação entre os Objetivos e Métodos de Pesquisa

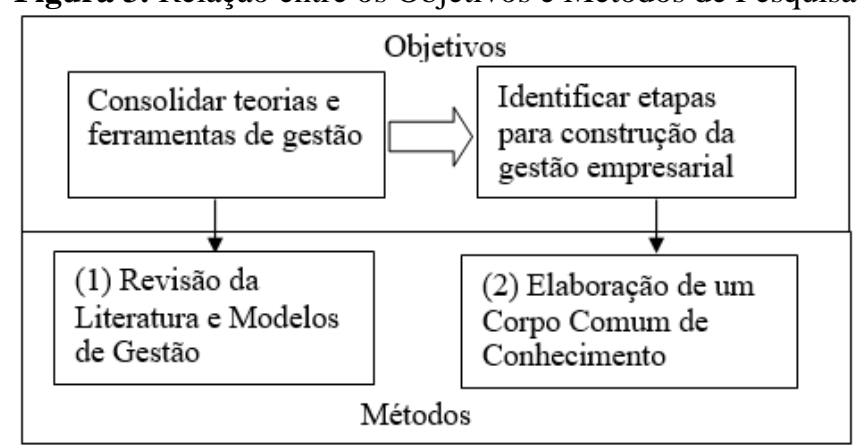

Fonte: Elaborada pelos autores.

\subsection{Revisão da Literatura e Modelos de Gestão}

A primeira fase é composta pela revisão de conceitos, ferramentas e modelos de gestão. Sua motivação é apontar cada uma das etapas e atividades apontadas como criticas para a gestão empresarial.

Como destacado no referencial teórico, é importante que a etapa de revisão aprofunde o conhecimento, inicialmente, em dois conceitos: (1) melhoria contínua e (2) modelo de gestão. Para enfim abordar a (3) gestão estratégica, (4) tática e (5) operacional.

Assim, os modelos e ferramentas abordados neste estudo foram:

Quadro 2. Modelos Selecionados para o Estudo

\begin{tabular}{|c|l|lr|}
\hline & \multicolumn{1}{|c|}{ Método } & \multicolumn{2}{|c|}{ Autor } \\
\hline 1 & $\begin{array}{l}\text { Plan, Do, } \\
\text { Check, } \text { Act } \\
\text { (PDCA) }\end{array}$ & $\begin{array}{l}\text { SHEWHART (1939); FALCONI } \\
\text { (2013); HOSOTANI (1992); } \\
\text { MARANHÃO e MACIEIRA (2008); } \\
\text { NASCIMENTO (2011); }\end{array}$ \\
\hline 2 & $\begin{array}{l}\text { Modelo de } \\
\text { Excelência } \\
\text { da Gestão } \\
\text { (MEG) }\end{array}$ & FNQ (2008, 2012, 2013) \\
\hline 3 & $\begin{array}{l}\text { Balanced } \\
\text { Scorecard } \\
\text { (BSC) }\end{array}$ & $\begin{array}{l}\text { KAPLAN e NORTON (1997, 2004); } \\
\text { GIMENEZ et al. (1999); } \\
\text { MINTZBERG (2006); }\end{array}$ \\
\hline
\end{tabular}

\begin{tabular}{|l|l|l|}
\hline \multirow{4}{*}{4} & $\begin{array}{l}\text { Business } \\
\text { Model } \\
\text { Canvas }\end{array}$ & $\begin{array}{l}\text { OSTERWALDER e PIGNEUR } \\
\text { (2010); DIAS et al. (2006); HSM } \\
\text { (2016); OSTERWALDER (2004); }\end{array}$ \\
\hline \multirow{5}{*}{5} & $\begin{array}{l}\text { Business } \\
\text { Process } \\
\text { Management } \\
\text { (BPM) }\end{array}$ & $\begin{array}{l}\text { ABPMP (2013); KANG et al. (2012); } \\
\text { MINONNE (2012); NEUBAUER } \\
(2009) ; \text { PAIM et al. (2008); SORDI } \\
(2008) ; \text { STRNADL (2006); }\end{array}$ \\
\hline
\end{tabular}

Fonte: Elaborada pelos autores.

Selecionados pela relevância na literatura moderna da área e sua aderência ao mercado. Porém, é importante salientar que a restrição adotada por apenas 5 métodos e ferramentas deve ser considerada uma limitação do estudo.

\subsection{Elaboração de um Corpo Comum de Conhecimento}

Com base nas revisões da literatura, e consecutiva identificação das atividades importantes para a empresa, consolida-se uma única sequência de etapas para estruturação da gestão empresarial.

$\mathrm{O}$ diagrama abaixo mostra a sequência dos procedimentos metodológicos.

Figura 4. Fluxograma do Procedimento Metodológico

\begin{tabular}{c|c|c|} 
Modelos \\
Existentes
\end{tabular}$\rightarrow \begin{gathered}\text { Temas e } \\
\text { Etapas em } \\
\text { Comum }\end{gathered} \rightarrow \stackrel{\begin{array}{c}\text { Consolidação } \\
\text { em Modelo } \\
\text { Único }\end{array}}{\longrightarrow}$

Fonte: Elaborada pelos autores.

As setas no diagrama significam que há ordem lógica para se atingir a consolidação das Sugestões de Etapas para uma Gestão Empresarial - objetivo central desta pesquisa. Primeiramente, realiza-se uma revisão na literatura dos modelos existentes, bem como adequada análise, para que somente na sequência, e como proposto nesta última etapa metodológica, todo o conhecimento levantado sintetize um corpo único de conhecimento.

\section{Análise Individual dos Métodos}

\subsection{Ciclo Plan, Do, Check, Act (PDCA)}

O método PDCA deve ser utilizado na organização como um todo, de modo sistêmico, somente dessa forma o crescimento de longo prazo será alcançado (FALCONI, 2013). Falconi (2013) aponta a existência de dois tipos de metas em qualquer organização: resultados que desejamos

Revista de Negócios, v. 21, n. 3-4, p. 39-51, July, 2016. 
melhorar e resultados que desejamos manter. Nos dois casos utiliza-se o PDCA, como mostra a Figura 5. $\mathrm{O}$ autor prossegue afirmando que qualquer resultado de melhora deve ser imediatamente estabilizado nas operações, onde, para estes que desejamos manter, denomina-se SDCA; visto que na operação o plano $(\mathrm{P})$ é o padrão (de Standardize).

Figura 5. Modelo do Método PDCA utilizado para operar de forma consistente e melhorar a operação de uma organização

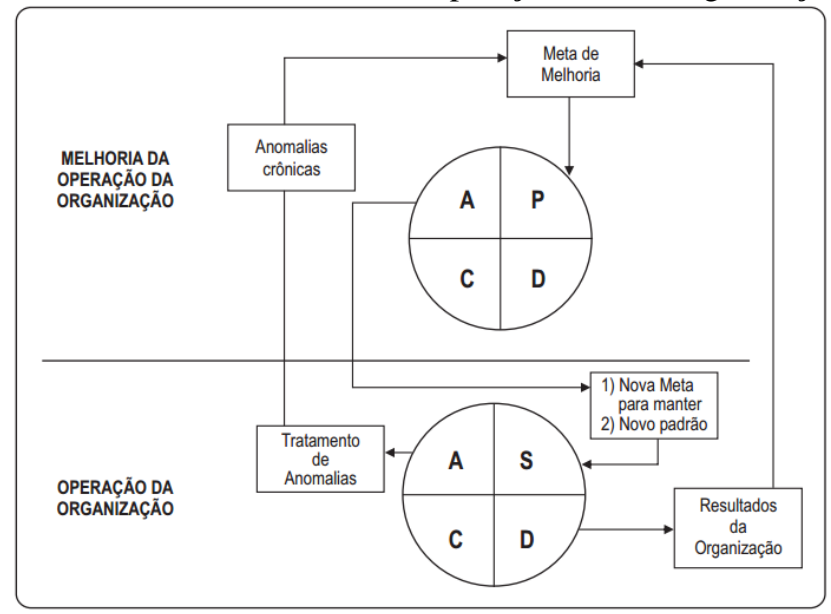

Fonte: Falconi (2013).

Ampliando este conceito é possível perceber a organização como um grande sistema de gestão, com metas e melhorias a níveis estratégico, tático e operacional. Garantindo que as metas do diretor estejam diretamente ligadas às metas de sua chefia (FALCONI, 2013) num relacionamento de causa e efeito, tangibilizados na figura 6.

Figura 6. Modelo do método PDCA utilizado para operar uma organização e para melhorar a operação

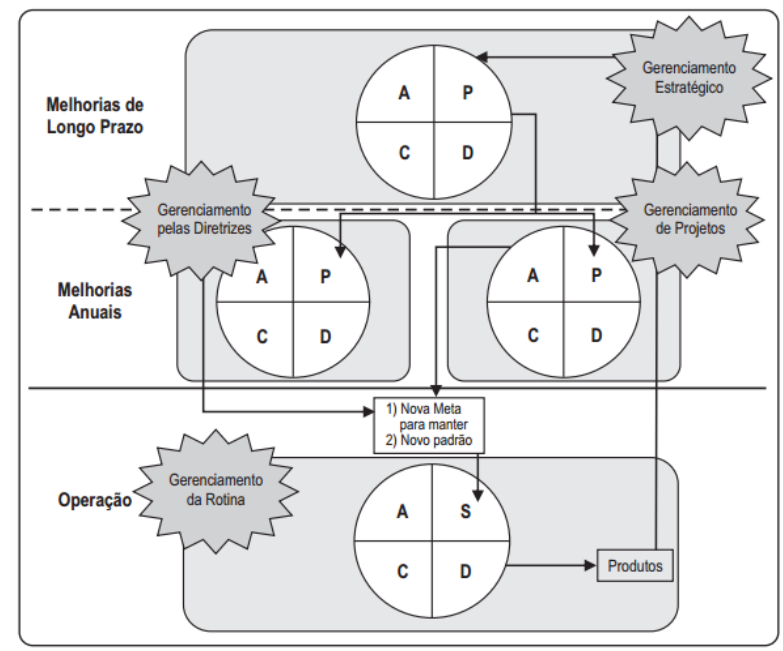

Fonte: Falconi (2013).

É preciso ressaltar que o ciclo PDCA tem sido amplamente utilizado no ensino de administração, compondo parte da ementa de matérias intituladas "Teoria Geral da Administração". Assim como tem sido utilizado para planejamento e melhoria de atividades operacionais e de gestão.

O modelo apresenta um ponto positivo muito forte: o fato de se encaixar em organizações com diversos níveis de maturidade e tamanho. No entanto, essa característica abrangente exige, para uma boa aplicação, conhecimento por parte do gestor sobre as áreas especificas a serem trabalhadas. O modelo não prescreve o que é um planejamento dentro de uma organização, quais pontos deve abranger, como definir as metas ou se deve traçar entregáveis ao final do ciclo. Assim como não prescreve informações do tipo para as demais etapas.

Pode-se concluir que o método PDCA é um modo de pensar, um conceito sobre a gestão, mas que por não conter especificidades dentro de suas etapas precisa de ferramentas complementares para ser implementado em pequenas e médias empresas.

\subsection{Modelo de Excelência da Gestão (MEG)}

O MEG pode ser representado conforme a imagem a seguir:

Figura 7. Representação do Modelo de Excelência da Gestão®

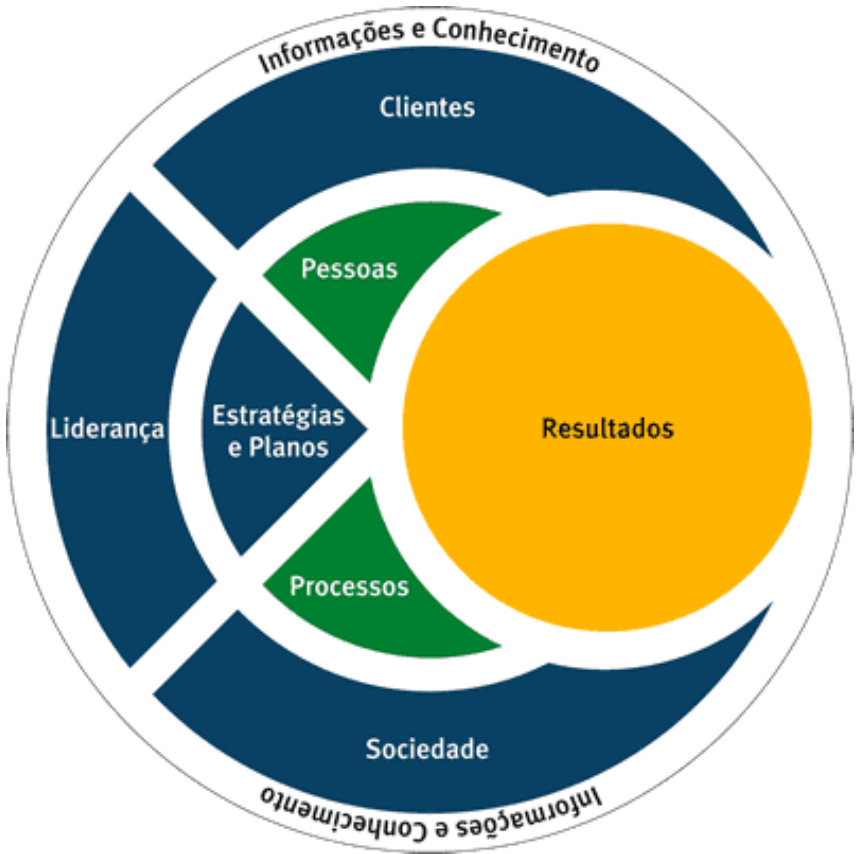

Fonte: FNQ, Critérios de Excelência (2013).

Figura que pode ser entendida segundo a lógica: o direcionamento da organização, dado pela

Revista de Negócios, v. 21, n. 3-4, p. 39-51, July, 2016. 
Liderança, ouvindo os Clientes e a Sociedade, é definido por meio das Estratégias e Planos; a sua implementação é realizada por meio das Pessoas, que compõem a força de trabalho, utilizando-se dos Processos existentes na organização; e todo esse ciclo, ao ser executado, deverá conduzir a Resultados, que devem ser analisados e entendidos, gerando Informações e Conhecimento para serem utilizados no processo de tomada de decisão, gerando um novo ciclo de gestão (FNQ, 2008).

A organização que seguir tais critérios, e o modo de interpretá-lo, como descrito a cima deve evoluir em seu nível de maturidade da gestão, internalizando os fundamentos de excelência da gestão. É importante salientar que quanto mais os fundamentos estiverem intrínsecos no modelo de gestão mais a organização caminha ao nível de excelência das classes mundiais (FNQ, 2013). Conforme gráfico a seguir:

Figura 8. Evolução e estágios de maturidade da gestão NIVELL DE MATURIDADE DA GESTĀo

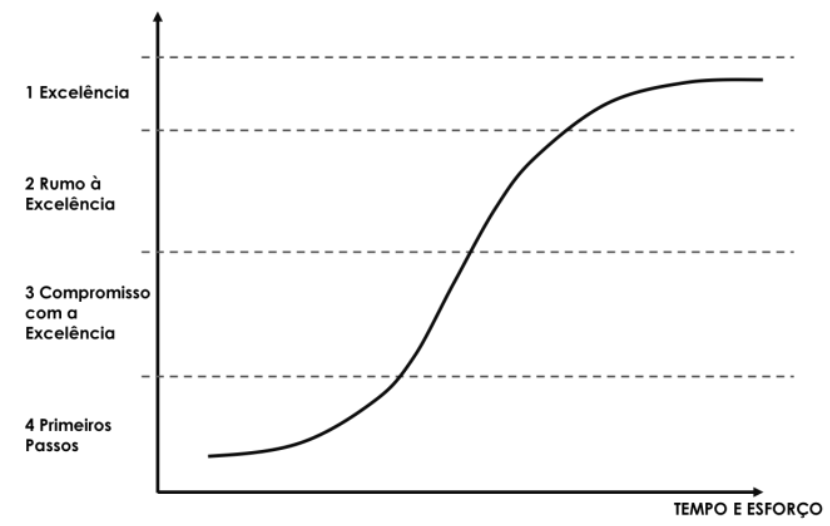

Fonte: FNQ, Critérios de Excelência (2013).

O Modelo de Gestão concebido pela Fundação Nacional da Qualidade possui aspectos muito positivos em tratar o conceito de forma extremamente completa, clara e inovadora. Primeiro trata de critérios pelos quais uma organização precisa passar para possuir um modelo de gestão de excelência, para enfim citar os fundamentos que deverão ser institucionalizados nesse percurso. Além disso o modelo é constantemente revisado com base nas organizações de classe mundial (FNQ, 2013) remetendo a consistência das informações utilizadas pela FNQ. Sendo base para o maior prêmio nacional de excelência de gestão.

Embora o modelo prescreva a ordem de causa e efeito que a gestão percorre até atingir seus resultados ele não se propõe a prescrever o que deve ser realizado para se obter determinado nível de excelência. Como não é restrito a PMEs, ele não elenca as boas práticas dentro dos critérios levantados para tal perfil de organização.

Pode-se concluir que o MEG demonstra o modelo de gestão a ser seguido de forma ampla, com direcionamentos para qualquer organização identificar, dentro de sua realidade, como implementar e operacionalizar cada fundamento e critério.

\subsection{Balanced Scorecard (BSC)}

O Balanced Scorecard traduz os objetivos do mapa estratégico em indicadores e metas. Mas estes objetivos e metas não serão alcançados apenas porque foram identificados, a organização deve lançar um conjunto de programas que criarão condições para que se realizem as metas de todos os indicadores (KAPLAN; NORTON, 2004). Ainda, segundo os autores, a organização deve fornecer os recursos escassos - pessoas, financiamento e capacidade - para cada programa.

Para cada indicador do Balanced Scorecard, os gerentes precisam identificar as iniciativas estratégias necessárias para alcançar a meta (Figura 9).

Figura 9. O Balanced Scorecard Fornece a Estrutura Necessária para a Tradução da Estratégia em Termos Operacionais

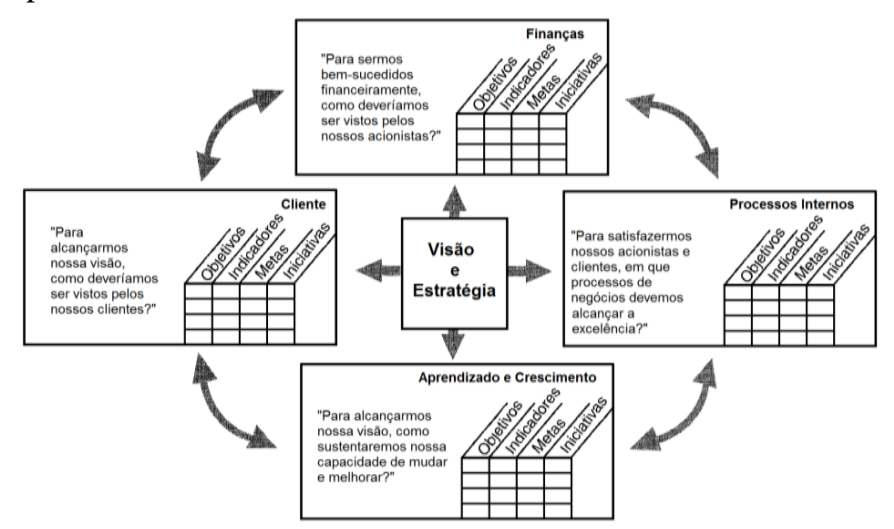

Fonte: Kaplan; Norton (1997)

As iniciativas criam resultados e assim a execução da estratégia é gerenciada por meio do acompanhamento das inciativas estratégicas. (KAPLAN; NORTON, 2004)

O modelo coloca o resultado tangível, tanto financeiro como de clientes, como consequência de uma gestão de intangíveis e processos que entregam valor, indicando a necessidade de integração entre as diversas perspectivas de uma

Revista de Negócios, v. 21, n. 3-4, p. 39-51, July, 2016. 
organização.

Um segundo fator positivo é que o modelo traz o desdobramento necessário para a implementação e acompanhamento dos objetivos estratégicos em seus diversos níveis, se mostrando um modelo completo. $\mathrm{O}$ que justifica sua notoriedade acadêmica e de mercado, tornando-se a ferramenta mais famosa para gestão estratégia.

É importante salientar que o Mapa Estratégico e o Balanced Scorecard trazem um conceito de interpretação visual para a gestão, utilizando de diagramas de causa e efeito, quadros e setas para sua elaboração. Isso reforça a necessidade de, mesmo em conceitos complexos, utilizar-se de conclusões que valham de entendimento para todos os colaboradores.

Por fim, pode-se concluir que é um modelo extremamente interessante de se utilizar. E que, embora não contemple a gestão como um todo, abrange grande parte do direcionamento e da gestão de alto nível de uma organização.

\subsection{Business Process Management (BPM)}

Um processo de negócios é um conjunto completo, com atividades coordenadas ou tarefas logicamente relacionadas que devem ser realizadas para oferecer valor aos clientes ou para cumprir outros objetivos estratégicos (STRNADL, 2006).

Organizações com capacidades robustas de BPM podem responder de forma mais rápida a desvios com base no acompanhamento do desempenho de processos interfuncionais (ABPMP, 2013), pois, "conhecer as atividades executadas na organização permite melhorar aspectos de consistência, padronização e adequação, além de estabelecer os fundamentos para avaliar e gerenciar as capacidades da organização" (ABPMP, 2013. p.26).

$\mathrm{Na}$ abordagem conhecida como gestão funcional a organização tem característica de silos com baixa capacidade de coordenação e baixa orientação a mercado (PAIM et al., 2008). O BPM não elimina as unidades funcionais, mas adota uma perspectiva horizontal para elas, dando prioridade à estruturação do fluxo de trabalho de ponta a ponta da organização, com ênfase nos interesses do cliente (PAIM et al., 2008).

Segundo a ABPMP (2013) as expectativas do cliente em torno da entrega do produto ou serviço direcionam as metas de desempenho do processo. Essas metas de mais alto nível são, por sua vez, decompostas em alvos de desempenho subjacentes que podem ser estabelecidos para o nível funcional e operacional.

Essa abordagem de gestão por processos apresenta diversos pontos positivos. Primeiro ela destaca a importância do cliente para a organização, inclusive para o alinhamento de expectativas com as metas internas. Segundo, o modelo propõe um alinhamento com a estratégia da organização dizendo que seus processos precisam estar orientados tanto ao cliente quanto ao que a organização deseja alcançar. Por fim, retrata a organização nos diversos níveis, desde o mais estratégico e seus processos de gerenciamento, passando por projetos de melhoria mais disruptiva, até atingir a operação do dia a dia.

Pode-se concluir que este é um modelo bastante completo. Abordando temas de estratégia, processos e melhoria de longo prazo. Extremamente interessante de ser trabalhado por mudar a ótica de como uma organização deve ser guiada, por sua cadeia de valor e resultados em vez de atividades funcionais. Porém, pode-se afirmar que é um modelo bastante complexo para pequenas empresas abordarem metodologicamente no seu dia a dia.

\subsection{Business Model Canvas}

A ferramenta canvas busca tangibilizar de maneira visual o modelo de negócio da organização, a lógica de criação, entrega e captura de valor (OSTERWALDER; PIGNEUR, 2011). Sendo formado por 9 componentes, descritos na quadro 3 com suas respectivas questões chave.

Quadro 3. Componentes de um Modelo de Negócio e as perguntas que ele busca responder

\begin{tabular}{|l|l|}
\hline \multicolumn{1}{|c|}{ Componente } & \multicolumn{1}{|c|}{ Explicação } \\
1. Segmento de & $\begin{array}{l}\text { Diferentes grupos de pessoas ou } \\
\text { organizações que uma empresa busca } \\
\text { alcançar e servir. }\end{array}$ \\
\hline $\begin{array}{l}\text { 2. Proposta de } \\
\text { Valor }\end{array}$ & $\begin{array}{l}\text { Pacote de produtos e serviços que criam } \\
\text { valor para um segmento de clientes } \\
\text { específico. }\end{array}$ \\
\hline $\begin{array}{l}\text { 3. Canais } \\
\text { Remo uma empresa se comunica e alcança } \\
\text { Relacionamento } \\
\text { com Cliente }\end{array}$ & $\begin{array}{l}\text { Tipos de relação que uma empresa estabelece } \\
\text { com Segmentos de Clientes Específicos. }\end{array}$ \\
\hline $\begin{array}{l}\text { 5. Fontes de } \\
\text { Receita }\end{array}$ & $\begin{array}{l}\text { Dinheiro que uma empresa gera a partir de } \\
\text { cada Segmento de Clientes. }\end{array}$ \\
\hline $\begin{array}{l}\text { 6. Recursos } \\
\text { Principais }\end{array}$ & $\begin{array}{l}\text { Recursos mais importantes exigidos para } \\
\text { fazer um Modelo de Negócios funcionar. }\end{array}$ \\
\hline
\end{tabular}

Revista de Negócios, v. 21, n. 3-4, p. 39-51, July, 2016. 


\begin{tabular}{|l|l|}
\hline $\begin{array}{l}\text { 7. Atividades- } \\
\text { Chave }\end{array}$ & $\begin{array}{l}\text { Ações mais importantes que uma empresa } \\
\text { deve realizar para fazer seu modelo de } \\
\text { negócio funcionar. }\end{array}$ \\
\hline $\begin{array}{l}\text { 8. Parcerias } \\
\text { Principais }\end{array}$ & $\begin{array}{l}\text { Fornecedores e os parceiros que põem o } \\
\text { Modelo de Negócio para funcionar. }\end{array}$ \\
\hline $\begin{array}{l}\text { 9. Estrutura de } \\
\text { Custo }\end{array}$ & $\begin{array}{l}\text { Custos envolvidos na operação de um } \\
\text { Modelo de Negócios. }\end{array}$ \\
\hline
\end{tabular}

Fonte: Elaborado pelos autores com base em Osterwalder e Pigneur (2011).

A aplicação do canvas tem ido além de gerar novos modelos de negócio ou revisar e atualizar os existentes (HSM, 2013), podendo ser utilizado por companhias para checar a realidade, como quando, por exemplo, veem-se em processo de fusão ou aquisição e querem saber se o modelo de negócio da outra empresa é compatível com o delas. Uma finalidade ainda mais diferente é o uso para gestão, em diversos departamentos da empresa conhecem-se aplicações na área financeira e na de recursos humanos, entre outras (HSM, 2013).

Osterwalder e Pigneur (2011) trazem uma utilização do quadro para planejamento de visão futura. O canvas pode ser preenchido em duas etapas: uma sobre como a organização se encontra hoje e outra sobre como a organização espera estar no futuro. Ressaltando que a mesma deverá criar um planejamento para partir da situação atual e chegar até a situação desejada.

O Business Model Canvas é extremamente didático, intuitivo e utiliza da colaboração entre os envolvidos para sua elaboração, justificando a grande fama que está atingindo ao redor do mundo. Este formato foca os esforços da organização em torno das discussões que mais contribuem para a empresa, os nove blocos, onde a partir de seu preenchimento o conjunto de informações diz mais sobre a organização do que qualquer outro modelo (cadeia de valor, lógica de receitas e despesas, entre outros).

Embora o modelo descreva muito bem a forma que uma empresa deve operacionalizar a entrega de valor aos seus clientes não se deve confundir com o modelo de gestão da organização como um todo.

\section{Resultados}

\subsection{Resultados referentes a Análise Metodológica}

Conforme discutido individualmente, em cada um dos modelos existem aspectos favoráveis e aspectos com possibilidades de melhoria. A Quadro 4 busca sintetizar esta discussão.
Quadro 4. Análise preliminar dos Modelos selecionados

\begin{tabular}{|c|c|c|c|}
\hline Método & $\begin{array}{l}\text { Área de } \\
\text { Origem }\end{array}$ & Aspectos Favoráveis & Limitações para o uso Gerencial \\
\hline $\begin{array}{l}\text { Plan, Do, } \\
\text { Check, Act } \\
\text { (PDCA }\end{array}$ & $\begin{array}{l}\text { Produção e } \\
\text { Qualidade }\end{array}$ & $\begin{array}{l}\text { Encaixe em diversos níveis de } \\
\text { maturidade de gestão; } \\
\text { Prevê crescimento continuo } \\
\text { de longo prazo; }\end{array}$ & $\begin{array}{l}\text { Não prescreve como uma gestão deve } \\
\text { olhar para cada etapa. }\end{array}$ \\
\hline $\begin{array}{l}\text { Modelo de } \\
\text { Excelência } \\
\text { da Gestão } \\
\text { (MEG) }\end{array}$ & $\begin{array}{l}\text { Gestão de } \\
\text { Organizaçốes }\end{array}$ & $\begin{array}{l}\text { Possui critérios específicos } \\
\text { que descrevem o que é } \\
\text { excelência de gestão; } \\
\text { Encaixe em diversos niveis de } \\
\text { maturidade de gestão; }\end{array}$ & $\begin{array}{l}\text { Não instrui o caminho de entrega de } \\
\text { valor, como os critérios } \\
\text { fundamentos apresentados } \\
\text { comunicam ou geram resultado. }\end{array}$ \\
\hline $\begin{array}{l}\text { Balanced } \\
\text { Scorecard } \\
\text { (BSC) }\end{array}$ & Finanças & $\begin{array}{l}\text { Foca os objetivos e planos de } \\
\text { ação em quatro perspectivas } \\
\text { bem definidas da organização } \\
\text { como todo; }\end{array}$ & $\begin{array}{l}\text { Desenvolve } \circ \text { operacional pautado } \\
\text { apenas pela estratégia, não alinhando } \\
\text { com as atividades da organização em } \\
\text { si. }\end{array}$ \\
\hline $\begin{array}{l}\text { Business } \\
\text { Process } \\
\text { Manageme } \\
\text { nt (BPM) }\end{array}$ & $\begin{array}{c}\text { Processos e } \\
\text { Operações }\end{array}$ & $\begin{array}{l}\text { Mostra a importância de se } \\
\text { amadurecer a gestão; } \\
\begin{array}{l}\text { Traz a importância do } \\
\text { alinhamento estratégico e } \\
\text { operacional; }\end{array}\end{array}$ & $\begin{array}{l}\text { Complexo, de modo que apenas quem } \\
\text { conhece os "jargões" consegue } \\
\text { utilizar; } \\
\text { Embora cite o alinhamento entre os } \\
\text { processos não diz como fazer. }\end{array}$ \\
\hline $\begin{array}{l}\text { Business } \\
\text { Model } \\
\text { Canvas }\end{array}$ & $\begin{array}{c}\text { Empreendedo } \\
\text { rismo }\end{array}$ & $\begin{array}{l}\text { Visual; rolaborativo; } \\
\text { interativo; fácil de elaborar; } \\
\text { ágil; completo para o que se } \\
\text { propõe. }\end{array}$ & $\begin{array}{l}\text { Retrata apenas a cadeia de valor da } \\
\text { organização e não a gestão como um } \\
\text { todo; } \\
\text { Não lida com outros niveis como } \\
\text { estratégia ou mesmo pessoas. }\end{array}$ \\
\hline
\end{tabular}

Fonte: Elaborado pelos autores.

Estas informações expõem os gargalos dos modelos e ferramentas para a concepção de uma sugestão de etapas para a gestão. Entende-se que os aspectos favoráveis devem ser mantidos, garantindo que a organização execute seu modelo de gestão com sucesso e passando pelas perspectivas estratégica, tática e operacional, além da melhoria contínua. Porém, a sugestão final consolidada - proposta dessa pesquisa - deve suprir as limitações apontadas para uso gerencial como um todo.

Quadro 5. Aspectos favoráveis em comum entre as metodologias selecionadas

\begin{tabular}{|c|c|c|c|c|}
\hline $\begin{array}{l}\text { Aspectos em } \\
\text { Comum }\end{array}$ & $\begin{array}{l}\text { Plan, Do, Check, } \\
\text { Act (PDCA) }\end{array}$ & $\begin{array}{c}\text { Modelo de } \\
\text { Excelência da } \\
\text { Gestão (MEG) }\end{array}$ & $\begin{array}{l}\text { Balanced Scorecard } \\
\text { (BSC) }\end{array}$ & $\begin{array}{c}\text { Business Process } \\
\text { Management } \\
\text { (BPM) }\end{array}$ \\
\hline $\begin{array}{l}\text { Modelo de } \\
\text { Excelência da } \\
\text { Gestão (MEG) }\end{array}$ & $\begin{array}{l}\text { Tratam da Gestão } \\
\text { como o todo, } \\
\text { mostrando que se } \\
\text { deve abordar de } \\
\text { modo completo }\end{array}$ & 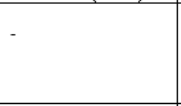 & - & 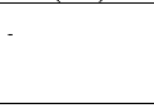 \\
\hline $\begin{array}{l}\text { Balanced } \\
\text { Scorecard (BSC) }\end{array}$ & $\begin{array}{lr}\text { Reforçam } & \text { a } \\
\text { necessidade } & \text { da } \\
\text { avaliação na } & \text { na } \\
\text { composição de um } \\
\text { modelo de gestão }\end{array}$ & $\begin{array}{l}\text { Importância de se } \\
\text { utilizar conhecimento } \\
\text { sobre pessoas e } \\
\text { processos para gerar } \\
\text { resultados }\end{array}$ & - & - \\
\hline $\begin{array}{l}\text { Business Process } \\
\text { Management } \\
\text { (BPM) }\end{array}$ & $\begin{array}{l}\text { Trabalham ciclos de } \\
\text { crescimento da } \\
\text { maturidade } \\
\text { empresarial e de } \\
\text { melhoria continua }\end{array}$ & \begin{tabular}{lrr|} 
Expõem que & os \\
fundamentos & da \\
gestão devem & ser \\
internalizados e fazer \\
parte do todo, não \\
tratados de forma \\
separada
\end{tabular} & $\begin{array}{l}\text { Mostram que a a } \\
\text { estratégia empresarial } \\
\text { é um norte a ser } \\
\text { executado alinhado a } \\
\text { operação }\end{array}$ & - \\
\hline $\begin{array}{l}\text { Business Model } \\
\text { Canvas }\end{array}$ & - & $\begin{array}{l}\text { Identificam de modo } \\
\text { prévio os assuntos a } \\
\text { serem discutidos e } \\
\text { trabalhados pela } \\
\text { gestâo }\end{array}$ & $\begin{array}{l}\text { Trazem conceito de } \\
\text { desenho visual aos } \\
\text { negócios, clareando a } \\
\text { percepção e criando } \\
\text { ordem lógica }\end{array}$ & $\begin{array}{l}\text { Evidenciam a } \\
\text { necessidade de } \\
\text { trabalhar a cadeia de } \\
\text { valor da empresa } \\
\text { orientada ao Cliente }\end{array}$ \\
\hline
\end{tabular}

Fonte: Elaborado pelos autores.

Uma forma de se apontar os devidos aspectos e etapas que devem estar presentes na gestão empresarial é a partir de algum método de priorização. O gráfico de Pareto é uma forma de dispor a informação tornando evidente e visual a priorização de temas. Ele permite direcionar esforços na melhoria de áreas onde os maiores ganhos podem ser obtidos (WERKEMA, 1995). Em uma análise qualitativa pode-se partir deste

Revista de Negócios, v. 21, n. 3-4, p. 39-51, July, 2016. 
princípio para identificar os aspectos (Quadro 5) e etapas (Quadro 6) recorrentes em mais de um modelo ou ferramenta estudado, supondo, assim, serem os mais importantes.

Com este levantamento torna-se factível suprir as limitações (apontadas no quadro 4) a partir dos aspectos positivos em comum aos modelos. Em linhas gerais, o quadro 5 aponta que um método para estruturação da gestão da gestão empresarial deve:

- Abordar de forma visual e sistêmica a gestão como um todo, desde o planejamento do que ser feito até retroalimentar de informações a organização com os resultados obtidos;

- Garantir que a organização cresça através de ciclos de maturidade, evoluindo de forma gradativa;

- Fazer os fundamentos do próprio método serem internalizados de modo a não ser uma ferramenta a parte da organização;

- Identificar de modo prévio as principais atividades (requisitos) que a organização precisa passar, porém sem restringir a liberdade de desenvolvimento organizacional;

- Fazer com que todos os colaboradores compreendam sua entrega de resultados como uma cadeia de eventos que geram resultados para o cliente e atinjam a visão de futuro da organização.

$\mathrm{O}$ que torna fundamental averiguar o que compõe tais aspectos (quadro 6).

Quadro 6. Pontos em comum entre as metodologias selecionadas

\begin{tabular}{|c|c|c|c|c|}
\hline $\begin{array}{c}\text { Pontos em } \\
\text { Comum }\end{array}$ & $\begin{array}{l}\text { Plan, Do, } \\
\text { Check, Act } \\
\text { (PDCA) }\end{array}$ & $\begin{array}{c}\text { Modelo de } \\
\text { Excelência da } \\
\text { Gestão (MEG) }\end{array}$ & $\begin{array}{c}\text { Balanced } \\
\text { Scorecard (BSC) }\end{array}$ & $\begin{array}{c}\text { Business Process } \\
\text { Management } \\
\text { (BPM) }\end{array}$ \\
\hline $\begin{array}{l}\text { Modelo de } \\
\text { Excelência da } \\
\text { Gestão (MEG) }\end{array}$ & $\begin{array}{l}\text { Planos de Ação; } \\
\text { Aprendizado } \\
\text { organizacional } \\
\text { (avaliação } \\
\text { melhoria) }\end{array}$ & 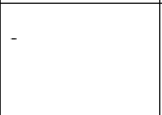 & - & 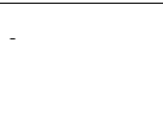 \\
\hline $\begin{array}{l}\text { Balanced } \\
\text { Scorecard (BSC) }\end{array}$ & $\begin{array}{l}\text { Visão } \\
\text { (Planejamento); } \\
\text { Iniciativas } \\
\text { (Executar); } \\
\text { Indicadores } \\
\text { (Avaliação); }\end{array}$ & $\begin{array}{l}\text { Pessoas } \\
\text { (responsáveis); } \\
\text { Visão de Futuro; }\end{array}$ & - & - \\
\hline $\begin{array}{l}\text { Business Process } \\
\text { Management } \\
\text { (BPM) }\end{array}$ & $\begin{array}{l}\text { Análise } \\
\text { (avaliação); } \\
\text { Melhoria; }\end{array}$ & $\begin{array}{l}\text { Processos de } \\
\text { Negócio; Valor } \\
\text { para Cliente; } \\
\text { Pensamento } \\
\text { Sistêmico; } \\
\end{array}$ & \begin{tabular}{|l|} 
Visão Estratégica; \\
Missão Empresarial \\
orientada a Cliente; \\
Pessoas \\
(responsáveis) \\
\end{tabular} & - \\
\hline $\begin{array}{l}\text { Business Model } \\
\text { Canvas }\end{array}$ & $\begin{array}{l}\text { Atividades } \\
\text { Chave } \\
\text { (executar); }\end{array}$ & \begin{tabular}{lr|} 
Valor & para \\
Cliente; & \\
Parcerias & e \\
Fornecedores; & \\
\end{tabular} & 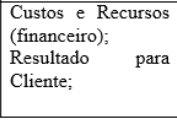 & $\begin{array}{l}\text { Proposta de } \\
\text { (missão } \\
\text { empresa); } \\
\text { Processos } \\
\text { Principais; }\end{array}$ \\
\hline
\end{tabular}

Fonte: Elaborado pelos autores.

Percebe-se, de acordo com as etapas levantadas, a existência de ao menos 5 (cinco) grandes focos nos modelos e ferramentas: visão de futuro, entrega de valor, atribuição de responsabilidades, controle de recursos e crescimento de longo prazo. Estes focos apenas sintetizam pontos de gestão, ou requisitos, presentes de forma conjunta em ao menos dois dos modelos e ferramentas estudados. Resumidos na quadro 7.

Quadro 7. Focos da gestão e principais requisitos organizacionais

\begin{tabular}{|l|l|l|}
\hline \multicolumn{1}{|c|}{ Foco da Gestão } & \multicolumn{1}{|c|}{ Tipo de Gestão } & \multicolumn{1}{c|}{ Requisitos Principais } \\
\hline Visão de Futuro & Gestão Estratégica & Visão; Objetivos; Iniciativas \\
\hline Entrega de Valor & Gestão de Processos & $\begin{array}{l}\text { Missão; Projetos Fim; Processos; } \\
\text { Relacionamento }\end{array}$ \\
\hline $\begin{array}{l}\text { Atribuição de } \\
\text { Responsabilidades }\end{array}$ & Gestão de Pessoas & Responsáveis \\
\hline $\begin{array}{l}\text { Controle de } \\
\text { Recursos }\end{array}$ & Gestão Financeira & $\begin{array}{l}\text { Entradas de Recursos; Saídas e } \\
\text { Custos }\end{array}$ \\
\hline $\begin{array}{l}\text { Crescimento de } \\
\text { Longo Prazo }\end{array}$ & Gestão de Melhoria & $\begin{array}{l}\text { Metas; Indicadores; Informações e } \\
\text { Conhecimento }\end{array}$ \\
\hline
\end{tabular}

Fonte: Elaborado pelos autores.

\subsection{Consolidação em Corpo Único de Conhecimento}

Com base nos requisitos consolidados pelo quadro 7 é possível apontar etapas (quadro 8) para sua construção, e consecutivamente da sugestão de gestão empresarial.

Quadro 8. Etapas para desenvolver requisitos de gestão

\begin{tabular}{|c|c|}
\hline Requisitos & Etapas \\
\hline $\begin{array}{lr}\text { Missão; } & \text { Projetos } \\
\text { Fim; Processos; } \\
\text { Relacionamento }\end{array}$ & $\begin{array}{l}\text { 1. Identificar Missão e proposta de Valor a Cliente } \\
\text { 4. Definir Projetos Fim } \\
\text { 6. Desenhar Fluxo de Trabalho }\end{array}$ \\
\hline Responsáveis & 7. Atribuir Responsáveis Pelas Atividades \\
\hline $\begin{array}{l}\text { Visão; Objetivos; } \\
\text { Iniciativas }\end{array}$ & $\begin{array}{l}\text { 2. Definir Visão de Longo Prazo } \\
\text { 3. Definir Objetivos Estratégicos } \\
\text { 5. Criar Iniciativas Estratégicas }\end{array}$ \\
\hline $\begin{array}{l}\text { Entradas de } \\
\text { Recursos; } \text { Saídas e } \\
\text { Custos }\end{array}$ & $\begin{array}{l}\text { 8. Entender Fontes de Captação e Saída de Capital } \\
\text { Financeiro }\end{array}$ \\
\hline $\begin{array}{l}\text { Metas; Indicadores; } \\
\text { Informações e } \\
\text { Conhecimento }\end{array}$ & $\begin{array}{l}\text { 9. Desenhar Indicadores para Coleta de } \\
\text { Informação } \\
\text { 10. Desenhar Metas para Garantir Resultados } \\
\text { 11. Aplicar Aprendizado e Conhecimento para } \\
\text { novo Planejamento }\end{array}$ \\
\hline
\end{tabular}

Fonte: Elaborado pelos autores.

Estas etapas, se alocadas em um modelo sequencial que garanta o crescimento e sustento de longo prazo, levarão a uma estruturação da gestão empresarial. O formato cíclico, como apontado pela revisão bibliográfica, garante tal crescimento. Assim, o método PDCA em conjunto com os 5 grupos de atividades (Visão de Futuro, Entrega de Valor, Atribuição de Responsabilidades, Controle de Recursos, Crescimento de Longo Prazo), garantirá que tais requisitos sejam abordados de forma lógica e consolidada em um mesmo modelo (figura 10). Pode-se afirmar que a Figura 10 apresenta a "forma", concebida por Ferreira et al. (2009) como a expressão da configuração

Revista de Negócios, v. 21, n. 3-4, p. 39-51, July, 2016. 
organizacional.

Figura 10. Comparativo entre Tipos de Gestão e Ciclo PDCA Ciclo PDCA Tipos (e Focos) da Gestão

\begin{tabular}{|c|c|c|}
\hline $\begin{array}{c}\text { Planejar } \\
\text { (Plan) }\end{array}$ & $\begin{array}{c}\text { Gestão de } \\
\text { Processos } \\
\text { (Entrega de Valor) }\end{array}$ & $\begin{array}{c}\text { Gestão } \\
\text { Estratégica } \\
\text { (Visão de Futuro) }\end{array}$ \\
\hline $\begin{array}{c}\text { Executar } \\
\text { (Do) }\end{array}$ & $\begin{array}{c}\text { Gestao de Pessoas } \\
\text { (Atribuicăo de } \\
\text { Responsabilidades) }\end{array}$ & $\begin{array}{c}\text { Gestão Financeira } \\
\text { (Controle de Recursos) }\end{array}$ \\
\hline $\begin{array}{c}\text { Avaliar } \\
\text { (Check) }\end{array}$ & & \\
\hline Melhorar & $\begin{array}{c}\text { Gestão de Melhoria } \\
\text { (Crescimento de } \\
\text { Longo Prazo) }\end{array}$ \\
\hline
\end{tabular}

Fonte: Elaborado pelos autores.

Assim, as atividades dentro da forma podem ser organizadas de modo correlacionado, fornecendo ao gestor um conjunto de ações que cobrem os diversos aspectos das decisões empresariais fundamentais às pequenas empresas. Emergindo a "função", tarefas que precisam ser cumpridas (FERREIRA et al., 2009), do modelo de estruturação da gestão empresarial, a seguir:

Figura 11. Etapas para Construção de uma Gestão Empresarial

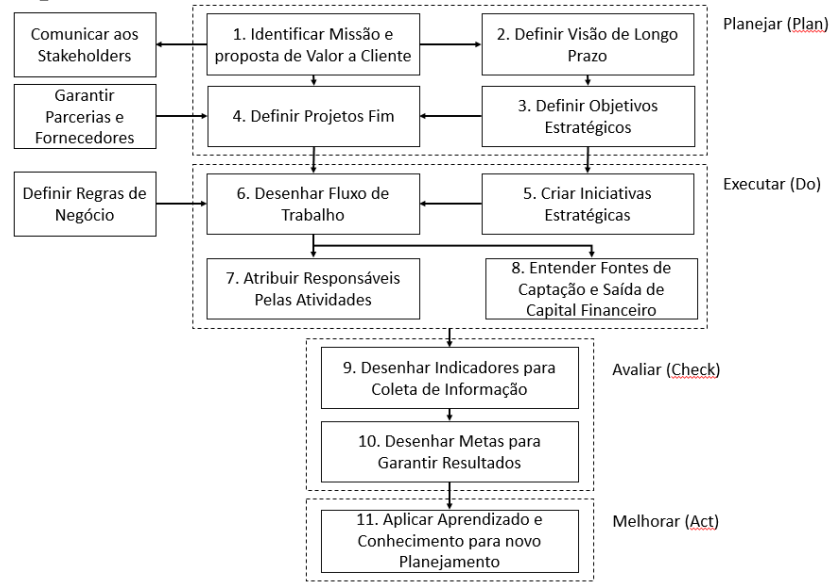

Fonte: Elaborado pelos autores.

Cabe algumas observações acerca dessa figura que sugere as etapas para a estruturação da gestão empresarial de pequenas empresas. Há atividades críticas para o negócio - comunicar valor aos stakeholders, garantir parcerias e fornecedores, definir regras de negócio - que mesmo sendo internas as etapas numeradas foram identificadas na literatura como importantes 0 bastante para um apontamento, de modo a ficarem expostas junto da sequência geral.

Uma segunda observação válida é que, uma organização nada mais é do que o equilíbrio entre os interesses do mercado (clientes e interessados em geral) com o interesse da organização (expectativas e capacidade produtiva), exposto pela dualidade das etapas "1" e "2". Não adianta uma organização querer atingir metas internas sem preocupar-se com a necessidade do cliente, porém também não seria prudente entregar tudo que o cliente deseja se não tiver capacidade produtiva para tal.

Por fim, este modelo difere dos demais por apresentar de modo consolidado tanto a configuração organizacional quanto as tarefas a serem cumpridas, ou seja, a forma e a função. Abordando de forma visual e sistêmica a gestão como um todo, ponto levantado como extremamente positivo durante a análise dos modelos existentes. Além de garantir que a organização cresça através de ciclos de maturidade.

\section{Considerações Finais}

Compreender o modelo e estrutura de gestão é de extrema relevância para a continuidade no longo prazo da empresa, visto que nele pode-se vislumbrar, além das práticas, a relação entre as atividades para se atingir um resultado a nível organizacional.

Resgatando as discussões anteriores percebese que a pergunta principal da pesquisa - Quais as etapas necessárias para a construção de uma estrutura de gestão empresarial? - foi respondida ao longo do Capítulo 5. Os quadros 4, 5, 6 e 7 trazem os pontos positivos, negativos, em comum e as etapas utilizadas pelos modelos e ferramentas de gestão estudadas, e ao final do capítulo, a Figura 11 traz a síntese do que são as Etapas sugeridas de forma consolidada.

É importante dizer que a pesquisa obteve um subproduto interessante, onde a comparação entre os modelos atuais gerou não apenas uma sugestão de etapas, mas também uma compreensão de quais são os focos de gestão de uma empresa, apresentados na Figura 10. Mostrando inclusive que uma organização pode ser definida pelo conflito de interesse entre as necessidades de mercado e dos gestores.

Apesar dos resultados alcançados, a pesquisa possui limitações. Assim, sugere-se realizar um aprofundamento do modelo proposto a partir de uma revisão sistemática dos artigos mais atuais sobre o tema, garantindo que nenhum aspecto atual importante da gestão de pequenas empresas fique

Revista de Negócios, v. 21, n. 3-4, p. 39-51, July, 2016. 
de fora. Além disso, seria interessante a realização de uma aplicação do modelo seguido por estudo de caso para averiguar o grau de efetividade na organização.

\section{Agradecimentos}

Os autores agradecem ao Conselho Nacional de Desenvolvimento Científico e Tecnológico

\section{Referências}

ABPMP. BPM CBOK - Guia para o Gerenciamento de Processos de Negócio. V3, ed.1, 2013

ALBAGLI, Sarita. Novos espaços de regulação na era da informação e do conhecimento. In: LASTRES, Helena M. M.; ALBAGLI, Sarita (org). Informação e globalização na era do conhecimento. Rio de Janeiro: Campus, 1999.

BARRETO, Oscar. A teoria do estabelecimento comercial. São Paulo: Saraiva, 1988, p. 115

BEDÊ, MARCO AURÉLIO (Coord.). Sebrae: sobrevivência das empresas no Brasil. Brasília: Sebrae, 2016.

CORDEIRO, Alexander Magno et al. Revisão sistemática: uma revisão narrativa. Rev. Col. Bras. Cir, v. 34, n. 6, p. 428-431, 2007.

DIAS, F.; MORGADO, G.; OSCAR, P.; SILVIERA, D.; JUAREZ, A.; LIMA, P. \& SCHMITZ, E. Uma Abordagem para a Transformação Automática do Modelo de Negócio em Modelo de Requisitos. Anais do WER06 - Workshop em Engenharia de Requisitos, Rio de Janeiro, RJ, Brasil, pp 51-60, 2006.

FALCONI, VICENTE. O Verdadeiro Poder. 2ed. - Nova Lima: FALCONI Editora, 2013.

FERREIRA ET AL. Modelos de Gestão. $3^{\mathrm{a}}$ ed. Rio de Janeiro: Editora FGV, 2009

FNQ. Cadernos Rumo a Excelência: Introdução ao Modelo de Excelência da Gestão ${ }^{\circledR}$ (MEG). São Paulo, 2008

FNQ. 20 anos da FNQ. São Paulo, 2012.
FNQ. Critérios de Excelência, avaliação e diagnostico da gestão organizacional. Ed.20, São Paulo, 2013

GIMENEZ, Fernando, A. P. et al. Estratégia em pequenas empresas: uma aplicação do modelo de Miles e Snow. RAC - Revista de Administração Contemporânea, v. 3, n. 2, p. 53-74, 1999.

HOSOTANI, KATSUYA. The $Q C$ problem solving approach: solving workspace problems. Quality Resources, 1992

HSM. O “canvas" do modelo de negócio. 2013 < http://experience.hsm.com.br/posts/o-canvas-do-

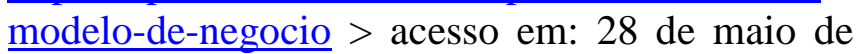
2016

KANG, S.; LEE, J.; LEE, D. and BAIK, J. A framework for measuring and managing value achievement in business process. IEICE Transactions on Information and Systems, Vol. E95-D No. 10, p. 2456-2468, 2012.

KAPLAN, R.; NORTON, D. Mapas Estratégicos, Convertendo Ativos Intangíveis em Resultados Tangíveis. Elsevier, 2004

KAPLAN, R.; NORTON, D. A estratégia em ação: balanced scorecard. Rio de Janeiro: Campus, 1997.

LA ROVERE, Renata Lèbre. As pequenas e médias empresas na economia do conhecimento. In: LASTRES, Helena M., ALBAGLI, Sarita (org.) Informação e globalização na era do conhecimento, Rio de Janeiro: Campus, 1999. p. 145-163.

MARANHÃO, Mauriti; MACIEIRA, B. Maria Elisa. O processo nosso de cada dia: modelagem de processos de trabalho. Rio de Janeiro: Qualitymark, 2008.

MINONNE, C. and TURNER, G. Business process management: are you ready for the future? Knowledge and Process Management, Vol. 19 No. 3, p. 111-120, 2012.

MINTZBERG, Henry et al. O processo da estratégia: conceitos, contextos e casos selecionados. Porto Alegre. Bookman, 2006.

Revista de Negócios, v. 21, n. 3-4, p. 39-51, July, 2016. 
NASCIMENTO, A. F. G. A utilização da metodologia do ciclo PDCA no gerenciamento da melhoria contínua. Tese (MBA em Gestão Estratégica da Manutenção, Produção e Negócios) ICAP-MG, Faculdade Pitágoras, Minas Gerais, 2011.

NEUBAUER, T. An empirical study about the status of business process management. Business Process Management Journal Bingley, v.15, n.2, p.166-183, 2009.

OSTERWALDER, ALEXANDER; PIGNNEUR, YVES. Business Model Generation - Inovação em Modelos de Negócios. Rio de Janeiro, RJ: Alta Book, 2011.

OSTERWALDER, ALEXANDER. The Business Model Ontology - A Proposition In A Design Science Approach. $\mathrm{PhD}$ thesis University of Lausanne. 2004

PAIM, R.C.S., CAULLIRAUX, H. and CARDOSO, R. Process management tasks: a conceptual and practical views. Business Process Management Journal, Vol. 14 No. 5, p. 694-723, 2008.

RODRIGUEZ, V.R. Martius. Gestão empresarial: organizações que aprendem. Rio de Janeiro: Qualitymark, 2010.

ROTHER, ET. Revisão sistemática $X$ revisão narrativa. Acta paulista de enfermagem. 2007; 20(2): v-vi.

SEBRAE-SP. 12 Anos de Monitoramento da Sobrevivência e Mortalidade de Empresas. São Paulo. Mímeo: Agosto,2010.

SEBRAE. Participação das Micro e Pequenas Empresas na Economia Brasileira. Brasília. Julho, 2014

SHEWHART, WALTER A. Statistical Method from the Viewpoint of Qualit. New York, 1939

SORDI, J. O. DE Gestão Por processos: uma abordagem da moderna administração. Saraiva, 2008. Cap. 2. linhas de direito econômico. Belo Horizonte: Fundação de Direito Econômico, 1977, p. 14.

STRNADL, C. F. Aligning business and it: The process-driven architecturemodel. Information Systems Management, 23(4), p.67-77. 2006.

TAYLOR, F. Principios da Administração Cientifica. Tradução de Arlindo Vieira Ramos sobre o original datado de 1911. São Paulo: Atlas, 1990

WERKEMA, M.C.C. Ferramentas estatísticas básicas para o gerenciamento de processos. Belo Horizonte: UFMG, 1995.

ZACCARELLI, Sérgio B. Estratégia e sucesso nas empresas. São Paulo: Saraiva, 2000.

SOUZA, Washington Peluso Albino de. Primeiras

Revista de Negócios, v. 21, n. 3-4, p. 39-51, July, 2016. 